\section{Exploring prospects of $\beta_{3}$-adrenoceptor agonists and inverse agonists for colon motility control}

\author{
Maria Grazia Perrone, \\ Marialessandra Contino, \\ Antonio Scilimati \\ Dipartimento di Farmacia-Scienze del \\ Farmaco, Università degli Studi di Bari A. \\ Moro, Bari, Italy
}

\section{Abstract}

Inverse agonists are useful active ingredient of drugs clinically used to treat diseases mainly involving receptors endowed with nonendogenous agonist induced activity (constitutive or basal activity). SP-1e and SP-1g are the first two potent and highly selective $\beta_{3}$-adrenoceptor inverse agonists $\left[\mathrm{EC}_{50}=181 \mathrm{nM}(\mathrm{IA}=-\right.$ $64 \%$ ) and $136 \mathrm{nM}$ (IA=-73\%), respectively], which their peculiar activity seems due to the absolute configurations of the two stereogenic centres present in each molecule. Rat proximal colon motility measurements allowed their further pharmacological characterization and $\mathrm{pA}_{2}$ values determination by Schild analysis (7.89 and 8.16 , respectively). The purpose of our work is a further characterization of our nove $\beta_{3}$-adrenoceptor agonists (SP-1a-d, SP-1f,1h) and inverse agonists (SP-1e and SP1g) on rat proximal colon motility and a confirmation of their inverse agonist nature in a more complex system like the functional test on rat proximal colon. Male Wistar rats segment of the proximal colon were placed in organ baths containing Krebs solution. Muscle tension was recorded isotonically. Cumulative $\beta_{3}$-AR agonists doses experiments were performed for each test compound: isoprenaline, BRL37344, SP-1a-d, SP-1f and SP-1h were dissolved in Krebs. The $\mathrm{EC}_{50}$ values of each agonists and $\mathrm{pA}_{2}$ of inverse agonists were determined. SP1a-d, SP-1f and SP-1h in rat colon have a muscle relaxing effect thus confirming their partial agonist activity found in CHO-K1 cell line. SP-1e and SP-1g behaved as antagonists with $\mathrm{pA}_{2}$ values of 7.89 and 8.16 , respectively. In conclusion, experiments carried out by using isolated rat proximal colon allowed us to determine the $\mathrm{pA}_{2}$ values of the two $\beta_{3}$-AR inverse agonists and add knowledge on the behavior of a novel set of compounds and their possible value as agents useful whenever is necessary to also control the colon motility.

\section{Introduction}

The gastrointestinal (GI) tract produces large amounts of catecholamines, which contribute to the regulation of gastrointestinal motility, secretion, local blood flow, and immune responses. ${ }^{1}$ It has been reported that both $\alpha$ - and $\beta$-adrenoceptors mediate noradrenaline-activated $\mathrm{K}^{+}$secretion in the distal colonic mucosa. ${ }^{2}$ It is generally accepted that catecholamines can relax gastrointestinal smooth muscle by acting on post-junctional $\alpha$ and $\beta$-adrenoceptors.

All three $\beta$-adrenoceptor subtypes are expressed in GI tract were they modulate also colon motility. In particular, $\beta_{1}$-adrenoreceptors are expressed in neurons and nerve fibres in both the myenteric and submucosal plexus in several species. The $\beta_{2}$-adrenoceptor is in rodent submucosal plexus neurons and nerve fibres, and in the mouse myenteric plexus. The $\beta_{3}$-adrenoceptors are localized on myenteric cholinergic neurons in the human colon and in nerve fibres of the rat myenteric plexus and deep muscular plexus where they were in close opposition to interstitial cells of Cajal. ${ }^{1}$

$\beta_{3}$-adrenoceptors ( $\beta_{3}$-AR) are widely distributed in the gastrointestinal tract of several species, including humans and rats. In particular, they are expressed on gut vascular and nonvascular smooth muscle, where they mediate relaxation and are probably involved in the control of blood flow. The $\beta_{3}$-AR modulates colonic motility, in particular, elevated tone and spontaneous contractions of isolated human colon are reduced and inhibited by $\beta_{3}-$ AR agonists such as SR 58611A or CGP $12177 \mathrm{~A},{ }^{3-5}$ respectively (Figure 1).

In addition, activation of $\beta_{3}$-AR by their agonists leads to an inhibition of cholinergic contractions and evokes somatostatine release, resulting in a decrease of intestinal motility and secretion, and inducing analgesia. ${ }^{6}$

$\beta_{3}$-AR displays a different degree of stereoselectivity towards several known traditional $\beta$ AR ligands. In particular, $\beta_{3}$-AR stereoselective dependency is lower for agonists such as isoprenaline and noradrenaline and is higher for antagonists (i.e. propranolol) than $\beta_{1}$ - and $\beta_{2}$ AR. ${ }^{7}$ We uncovered a set of new compounds that stereoselectively interact with $\beta_{3}-\mathrm{AR}{ }^{8}$

Novel compounds were assayed by measuring cAMP levels in CHO-kl cells expressing human cloned $\beta_{3}$-AR to determine their $\beta_{3}$-AR activity and as a result, novel potent and selective stereogenic $\beta_{3}$-AR agonists were disclosed together with the discovery of the first two potent and selective $\beta_{3}$-AR inverse agonists SP-1e and SP-1g was absolutely the most striking finding. 8,9

Herein, we report a further characterization of such compounds by measuring their effect
Correspondence: Antonio Scilimati, Dipartimento di Farmacia - Scienze del Farmaco, Università degli Studi di Bari A. Moro, via E. Orabona 4, 70125 Bari, Italy.

Tel. +39.080 .5442753 - Fax: +39.080 .5442724 .

E-mail: antonio.scilimati@uniba.it

Key words: $\beta_{3}$-adrenoceptor, agonists, inverse agonists, $\mathrm{CHO}$ cell line, rat proximal colon, gut disorders.

Funding: financial support was provided from the University of Bari and MiUR (PRIN 20097FJHPZ 001), that had no involvement in any activities related to the work.

Conflict of interests: the authors declare no potential conflict of interests.

Received for publication: 25 January 2013.

Revision received: 24 April 2013.

Accepted for publication: 24 April 2013.

This work is licensed under a Creative Commons Attribution NonCommercial 3.0 License (CC BYNC 3.0).

(C) Copyright M.G. Perrone et al., 2013

Licensee PAGEPress, Italy

Drugs and Therapy Studies 2013; 3:e5

doi:10.4081/dts.2013.e5

on ex vivo rat proximal colon. Colon motility modification is compromised in several diseases. ${ }^{10}$ Hence, it is crucial to know how physiological colon tone and contraction can pharmacologiclly be recovered.

\section{Materials and Methods}

\section{Statistics}

The $\mathrm{EC}_{50}$ values were obtained from non-linear iterative curve fitting by GraphPad Prism ${ }^{\circledR}$ 3.0. One way-ANOVA analysis of variance was used to estimate the significance of difference. $\mathrm{P}<0.05$ was considered statistically significant. The $\mathrm{pA}_{2}$ and slope values were calculated according to the method described by Arunlakshana and Schild. ${ }^{11}$

\section{Animals: experimental conditions}

Male Wistar rats weighing 300-350 g were killed by decapitation. The first $2.5-3.0 \mathrm{~cm}$ segment of the proximal colon, starting from the ileo-caecal junction, was dissected and quickly washed in saline and then placed in $20 \mathrm{~mL}$ organ baths containing Krebs solution (118 $\mathrm{mM} \mathrm{NaCl}, 4.7 \mathrm{mM} \mathrm{KCl}, 2.5 \mathrm{mM} \mathrm{CaCl} 2,1.2 \mathrm{mM}$

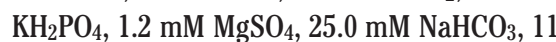
$\mathrm{mM}$ glucose) completed with $1 \mu \mathrm{M}$ phentolamine, $0.5 \mu \mathrm{M}$ desmethylimipramine and 30 
Table 1. Structures, absolute configurations and activity values of compounds SP-1-a-h measured in (CHO)-K1 cell line and in ex vivo rat colon.<smiles>[R]C(C)(O)Oc1ccc(CCNCC(O)c2ccccc2)cc1</smiles>

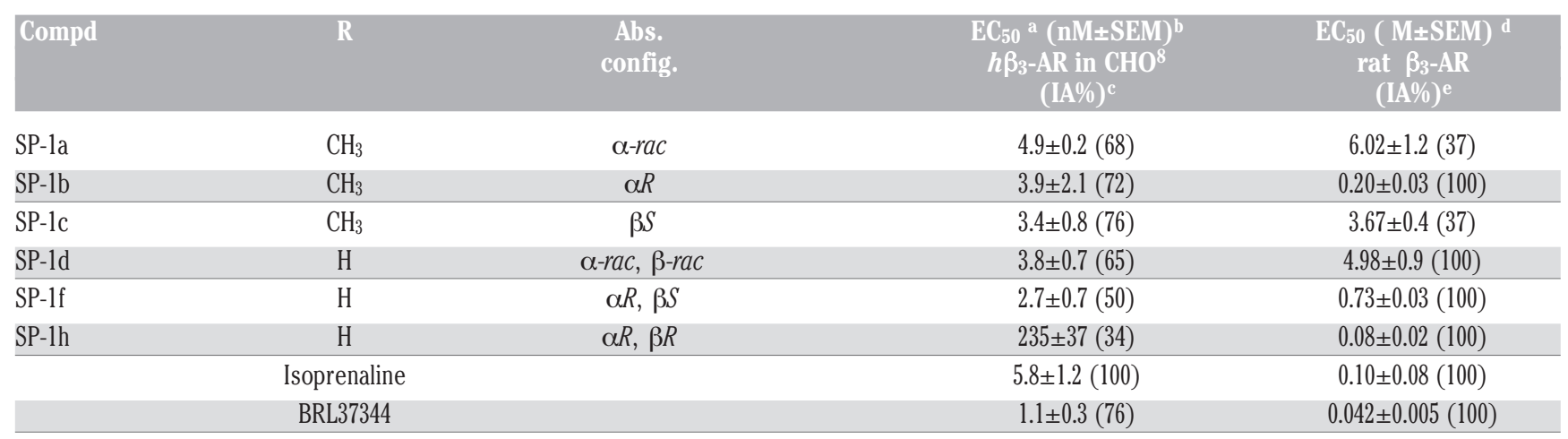

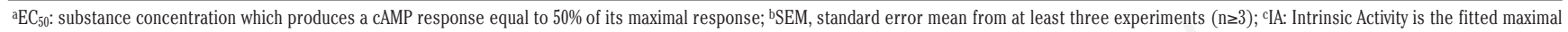
value of the concentration-response curve, expressed as a percent of the maximal response to $R-(-)$-isoproterenol $\left(10^{-4} \mathrm{M}\right)$. ${ }^{\mathrm{E}} \mathrm{EC}_{50}$ : substance concentration evaluated in functional test in which colon relaxation is

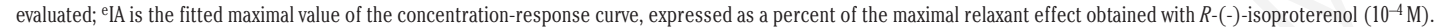

$\mu \mathrm{M}$ hydrocortisone (the latter two for preventing intraneuronal and extraneuronal uptake of catecholamines, respectively) at $37.0^{\circ} \mathrm{C}$ and bubbled with a $5 \% \mathrm{CO}_{2}$ and $95 \% \mathrm{O}_{2}$ gas. The bathing medium contained $1 \mu \mathrm{M}$ betaxolol and $1 \mu \mathrm{M}$ ICI118551 to block $\beta_{1}$ and $\beta_{2}$-AR, respectively. The strip was placed under a $1 \mathrm{~g}$ load, washed several times and allowed to develop stable spontaneous tone. Muscle tension was recorded isotonically using Fort 10 transducers original WPI, connected to a PowerLab 4/20 AD Instrument recorder.

After a three hours equilibration period, cumulative agonists doses experiments were performed for each test compound: isoprenaline, BRL37344, SP-1a-d, SP-1f and SP-1h were dissolved in Krebs and then cumulatively (10 nM, 50 nM, 100 nM, $0.5 \mu \mathrm{M}, 1 \mu \mathrm{M}, 3 \mu \mathrm{M}, 5$ $\mu \mathrm{M}, 10 \mu \mathrm{M}$ and $20 \mu \mathrm{M}$ ) added with an interval of 40 seconds between each dose. The concentration of agonists to produce a half maximal contraction $\left(\mathrm{EC}_{50}\right)$ was determined with a nonlinear curve fit program (GraphPad Prism ${ }^{\circledR}$ 3.0, GraphPad Software, Inc. San Diego, CA, USA) using the mean response of at least 3 separate trials. All animals were maintained in accordance with the guidelines for the care and use of laboratory animals of the Italian Ministry of Health.

\section{Results}

SP-1a-h behaviour strongly depends on the absolute configuration of the stereocentre(s) present in the molecules (Tables 1 and 2). In particular, SP-1a-d, SP-1f and SP-1h in rat colon have a muscle relaxing effect thus confirming their partial agonist activity found in
Table 2. Structures, absolute configurations and activity values of compounds SP1-e and SP1-g measured in (CHO)-K1cell line and in ex vivo rat colon.

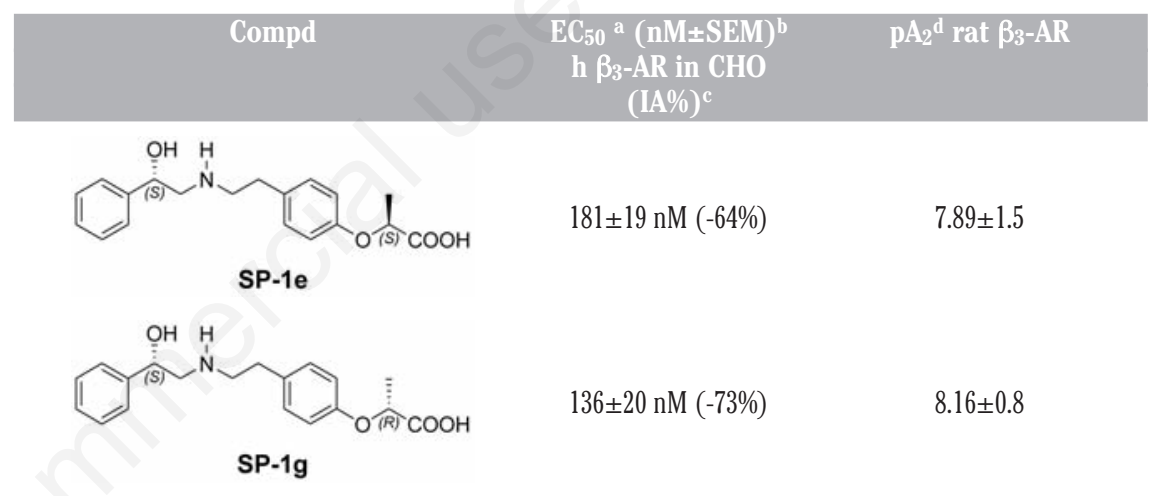

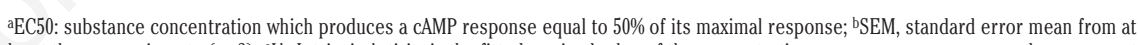
least three experiments $(\mathrm{n} \geq 3)$; ${ }^{\mathrm{C} I A}$, Intrinsic Activity is the fitted maximal value of the concentration-response curve, expressed as a percent of the maximal response to $R-(-)$-isoproterenol $\left(10^{-4} \mathrm{M}\right) ;{ }^{\mathrm{d}} \mathrm{pA}_{2}$ value of inverse agonists determined by using $R-(-)$-isoproterenol.

Table 3. Possible clinical use of $\beta_{3}-A R$ inverse agonists.

Metabolic In upper-body obese subjects with signs of the metabolic syndrome, $\beta_{3}$-AR (insulin resistance) blockade might preferentially inhibit fatty acid release from visceral adipose syndrome tissue and improve some of the metabolic abnormalities associated with the high portal fatty acid flux. ${ }^{12}$

\begin{tabular}{ll} 
Cachexia & $\begin{array}{l}\text { In cachectic cancer patients, the remarkable loss in adipose tissue }(\sim 30 \% \text { of } \\
\text { pre-illness stable weight at diagnosis) seems to be mediated by a lipid } \\
\text { mobilizing factor (LMF). Reported evidences demonstrate that, at least in } \\
\text { part, LMF produces this effect by interaction with } \beta_{3} \text {-AR. }{ }^{21}\end{array}$ \\
\hline Heart failure & $\begin{array}{l}\text { Selective } \beta_{3} \text {-AR agonists should serve in the early stage of heart failure, } \\
\text { whereas highly selective antagonists/inverse agonists might be useful in the } \\
\text { advanced stage of the disease. }\end{array}$
\end{tabular}<smiles>CCOC(=O)COc1ccc2c(c1)C[C@@H](NC[C@H](O)c1cccc(Cl)c1)CC2</smiles>

SR 58611A<smiles>CC(C)(C)NCC(O)COc1cccc2[nH]c(=O)[nH]c12</smiles>

CGP 12177A
Figure 1. SR 58611A and CGP 12177A $\beta_{3}-A R$ agonist chemical structures. 
A

AGONIST

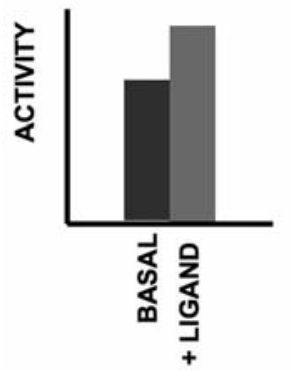

NEUTRAL ANTAGONIST

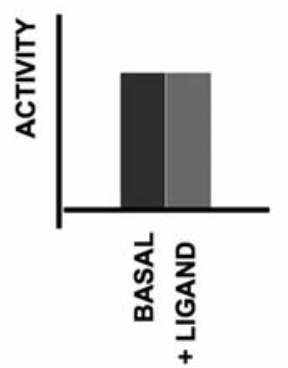

INVERSE AGONIST

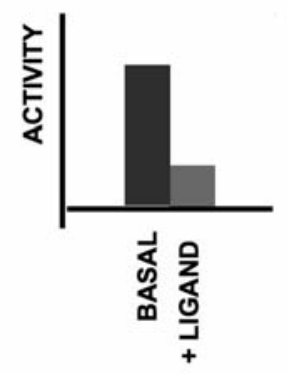

Figure 2. Inverse agonists are ligands that, by binding to a constitutively activated receptor, reduce or suppress its basal activity thus shifting a cell signaling cascade in the opposite direction to that produced by an agonist.

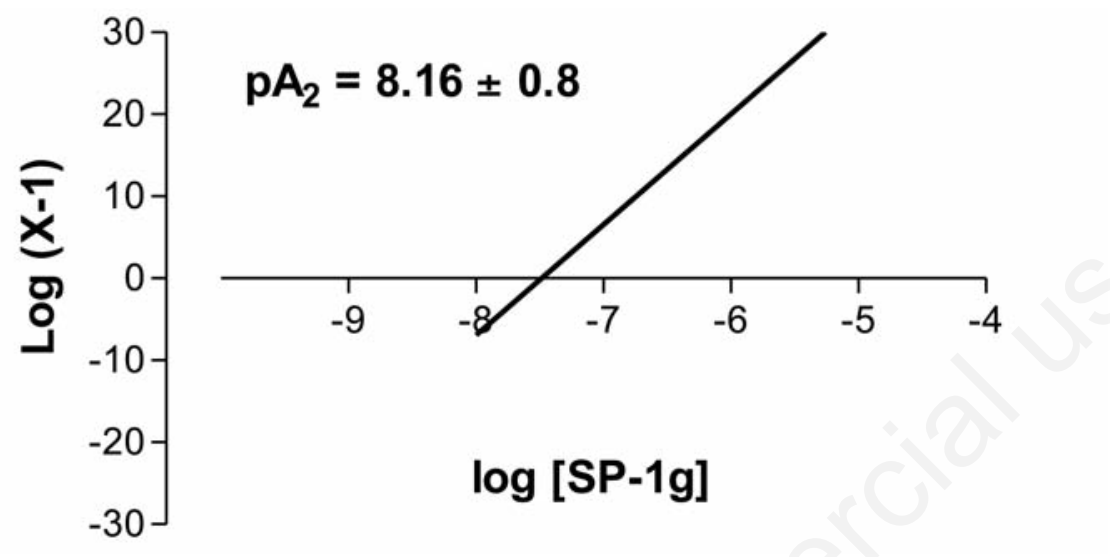

Figure 3. Schild plots of SP-1e and SP-1g in the rat proximal colon. All experiments are in triplicates and the $\mathrm{pA} 2$ values are expressed as the mean \pm SEM.

CHO-K1 cell line. ${ }^{8}$ The different $\mathrm{EC}_{50}$ and intrinsic activity values between $\mathrm{CHO}$ and rat colon are mainly due to the sequence difference of human and rat receptor, particularly located in the binding site.

SP-1b, in ex vivo experiments (Table 1), was found to be a full agonist $\left(\mathrm{EC}_{50}=0.20 \mu \mathrm{M}\right.$ and $\mathrm{IA}=100 \%$ ) with respect to the corresponding racemic form SP-1a $\left(\mathrm{EC}_{50}=6.02 \mu \mathrm{M}\right)$ and its $\alpha \mathrm{S}$ - enantiomer SP-1c $\left(\mathrm{EC}_{50}=3.67 \mu \mathrm{M}\right)$ which instead behaved as partial agonists (IA=37\%) thus confirming that the configuration at $\mathrm{C} \alpha$ is generally $(R)$ in $\beta_{3}$ - $\mathrm{AR}$ agonists.

Compounds with two stereocentres, such as SP-1d, SP-1f and SP-1h were found to be ful agonists at rat colon and endowed with different potencies, $4.98 \mu \mathrm{M}$ for the racemic form SP-1d, $0.73 \mu \mathrm{M}$ for $\alpha R, \beta S$-SP-1f and $0.08 \mu \mathrm{M}$ for $\alpha R, \beta R$-SP-1h.

The $\beta_{3}$-AR inverse agonists SP-1e (5 M) and SP1g $(5 \mu \mathrm{M})$ were pre-incubated for 15 min and then the effect of the addition of isoprenaline was evaluated. Their potency was determined plotting the suitable results to perform the Schild analysis. The $\mathrm{pA}_{2}$ values [ $-\mathrm{log}$ (Antagonist)] were determined by a linear curve fit program (GraphPad Prism ${ }^{\circledR}$ 3.0) using the mean response of at least 3 separate experiments. $(\alpha S, \beta R)$-SP-1g was found to be the most potent inverse agonist with an $\mathrm{EC}_{50}=136 \mathrm{nM}$ and $\mathrm{IA}=-63 \%$. Its epimer $(\alpha S$, $\beta S$ )-SP-1e had comparable potency and intrinsic activity $\left(\mathrm{EC}_{50}=181 \mathrm{nM}, \mathrm{IA}=-64 \%\right)$ (Table 2).

\section{Discussion}

The $\beta_{3}$-AR, like the other $\beta$-AR subtypes, is a seven-transmembrane domain (7TD) G-protein coupled receptor (GPCR). It is usually coupled to a Gs protein and its stimulation increases the production of cAMP. ${ }^{12}$ On the other hand, in the human heart the signal of $\beta_{3}$-AR is transduced by the Gi-eNOS-NOcGMP pathway and produce negative inotropic effect. ${ }^{13-14} \mathrm{~A}$ lot of $\beta_{3}$-AR agonists have been uncovered and extensively characterized. ${ }^{15}$ Conversely, very little is known about $\beta_{3}-\mathrm{AR}$ inverse agonists. ${ }^{16,17}$ Inverse agonism is not a new concept and it describes ligand behavior displaying negative efficacy. ${ }^{18}$ In particular, for
GPCRs, it has been widely assumed that inverse agonists suppress the agonist-independent activity (constitutive activity) of the receptor by stabilizing it in its inactive state (Figure 2). ${ }^{19}$

Novel findings suggest that some classical $\beta$-AR antagonists behave either as partial agonists, neutral antagonists, or inverse agonists in cell systems expressing the wild type or a constitutively activated mutant of the human $\beta$-AR. For example, selective $\beta_{1}$-AR antagonists with significant inverse agonistic activity, in rat myocardium, such as metoprolol, ${ }^{20}$ have been proved to be safe in the treatment of heart failure. Very little is known about $\beta_{3}-\mathrm{AR}$ inverse agonists, but they could have different possible clinical applications (Table 3 ). ${ }^{16-17,21}$

Knowing the potential therapeutic applications of $\beta_{3}$-AR inverse agonists, it was crucial a further characterization of our two compounds and a confirmation of their inverse agonist nature in a more complex system like the functional test on rat proximal colon. SP-1e and SP-1g behaved as antagonists (in functional test in which colon motility is evaluated, it is not possible to discriminate antagonism from inverse agonism). Schild analysis allows to determine $\mathrm{pA}_{2}$ values (Table 2, Figure 3).

\section{Conclusions}

In conclusion, experiments carried out by using isolated rat proximal colon allowed us to determine the $\mathrm{pA}_{2}$ values of the two $\beta_{3}$-AR inverse agonists. The behavior of a novel set of compounds add knowledge on their possible value as agents useful whenever is necessary also to control the colon motility.

\section{References}

1. Lomax AE, Sharkey KA, Furness JB. The participation of the sympathetic innervation of the gastrointestinal tract in disease states. Neurogastroenterol Motil 2010;22: 7-18.

2. Schultheiss G, Diener M. Adrenoceptormediated secretion across the rat colonic epithelium. Eur J Pharmacol 2000;403: 251-8.

3. De Ponti F, Cosentino M, Costa A, et al. Inhibitory effects of SR 58611A on canine colonic motility: Evidence for a role of beta 3-adrenoceptors. Br J Pharmacol 1995;114: 1447-53.

4. Perrone MG, Notarnicola M, Caruso MG, et al. Upregulation of $\beta_{3}$-adrenergic receptor mRNA in human colon cancer: a preliminary study. Oncology 2008;75:224-9.

5. Perrone MG, Scilimati A. $\beta_{3}$-Adrenoceptor 
ligand development history through patent review. Expert Opin Ther Pat 2011;21:50536.

6. Cellek S, Thangiah R, Bassil AK, et al. Demonstration of functional neuronal $\beta_{3}$ adrenoceptors within the enteric nervous system. Gastroenterology 2007;133:175-83.

7. Dallanoce C, Frigerio F, De Amici M, et al. Novel chiral isoxazole derivatives: synthesis and pharmacological characterization at human beta-adrenergic receptor subtypes. Bioorg Med Chem 2007;15:2533-43.

8. Perrone MG, Santandrea E, Bleve L, et al. Stereospecific synthesis and bio-activity of novel $\beta_{3}$-adrenoceptor agonists and inverse agonists. Bioorg Med Chem 2008;16:2473-88.

9. Perrone MG, Scilimati A. $\beta_{3}$-adrenoceptor agonists and (antagonists as) inverse agonists: history, perspective, constitutive activity, and stereospecific binding. Methods Enzymol 2010;484:197-230.

10. Schemann M, Hafsi N, Michel K, et al. The $\beta_{3}$-Adrenoceptor Agonist GW427353
(Solabegron) decreases excitability of human enteric neurons via release of Somatostatin. Gastroenterology 2010;138: 266-74.

11. Lazareno S, Birdsall NJM. Estimation of competitive antagonist affinity from functional inhibition curves using the Gaddum, Schild and Cheng-Prusoff equations. Br J Pharmacol 1993;109:1110-9.

12. Strosberg AD. The $\beta_{3}$-adrenoreceptor. New York: Taylor \& Francis; 2000.

13. Gan RT, Li WM, Xiu CH, et al. Chronic blocking of $\beta_{3}$-adrenoceptor ameliorates cardiac function in rat model of heart failure. Chin Med J (Eng) 2007;120:2250-5.

14. Pott C, Brixius K, Bloch W, et al. Beta 3adrenergic stimulation in the human heart: signal transduction, functional implications and therapeutic perspectives. Pharmazie 2006;61:255-60.

15. Hieble JP. Recent advances in identification and characterization of beta adrenoceptor agonists and antagonists. Curr Top Med Chem 2007;7:207-16.
16. Baker JG. Evidence for a secondary state of the human $\beta_{3}$-adrenoceptor. Mol Pharmacol 2005;68:1645-55.

17. Hoffmann C, Leitz M, Obendorf-Maass S, et al. Comparative pharmacology of human $\beta$-adrenergic receptor subtypes-characterization of stably transfected receptors in CHO cells. Naun Schmied Arch Pharmacol 2004;369:151-9.

18. Costa T, Cotecchia S. Historical review: negative efficacy and the constitutive activity of G-protein-coupled receptors. Trends Pharmacol Sci 2005;26:618-24.

19. Strange P. Mechanisms of inverse agonism at G-protein-coupled receptors. Trends Pharmacol Sci 2002;23:89-95.

20. Varma DR, Shen H, Deng XF, et al. Inverse agonist activities of $\beta$-adrenoceptor antagonists in rat myocardium. Br J Pharmacol 1999;127:895-902.

21. Tisdale MJ. Pathogenesis of cancer cachexia. J Support Oncol 2003;1:159-68. 